\title{
Labyrinth Seals - A Promising and Effective Design
}

\author{
Galina Ilieva
}

University of Beira Interior, 6201-001 Covilhã, Portugal

\begin{abstract}
Main task of this study is to fulfill numerical modeling and analysis of a labyrinth seals, which have geometry quite different than the ones applied up to now. The challenge was to arrive to a design for a seal that has good sealing properties, ease manufacturing, can sustain higher stress loading and perform increased loss of kinetic energy, as the idea is to stop the leaks. The fulfilled numerical analysis shows that the proposed geometry leads to high decrease of leakage flow rates and thus contributes to possibility to increase the efficiency performance of turbine stages as part of a propulsion system.
\end{abstract}

Keywords: Discharge coefficient, Labyrinth seal, Numerical modeling, Vortex structure

\section{Introduction}

Turbines are widely applied in marine propulsion, aircraft propulsion, power plants and other industrial areas. In recent years, the power requirements are significantly increasing, leading to the need of enhanced power, delivered by the turbine and higher efficiency.

It is well known that there exist losses of working fluid through axial and radial gaps in turbomachines, leading to less efficiency. It is stated in [1] that every $1 \%$ decrease in leakage flow through a high-pressure gas turbine seals would result in a $0.4 \%$ decrease in the specific fuel consumption. Last mentioned is a prerequisite to decreased fuel consumption and lead to higher economical benefits.

Last decades, a number of solutions have been found and applied to overcome those losses of working fluid in gas and steam turbines. One of those solutions is to use so called labyrinth seals as an obstacle on the way of flow leakages.

Placing labyrinth seals into these gaps leads to reduced leakage mass flow, thus increase the efficiency. In fig. 1 some examples of labyrinth geometries are shown [2]. The labyrinth seal arrangement at the blade tip consists of an inlet cavity, a series of closed cavities and an exit cavity. The size of the cavities can be relatively large in comparison to the blade size and channel height. This is in order to allow for the axial displacement of the rotor due to thermal growth or axial thrust variations.

The range of seals employed up to date can be classified into two categories - contact and non-contact seals [3]. Labyrinth seals are part of the group of non-contact seals. They are applied in steam and gas turbines and provide simple, but comparatively efficient sealing effect [5-8].

The labyrinth seals are as obstacle for the incoming flow of flow leaks passing through the seal. This results in significant kinetic energy dissipation in the form of turbulent vortices.

The labyrinth seals have advantages such as low maintenance, simple design, and efficient work, among others. One very important advantage is their long operational life due to their non-contacting nature of operation. a)

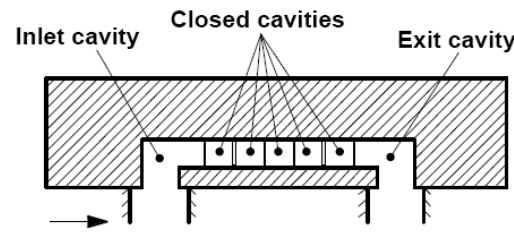

b)

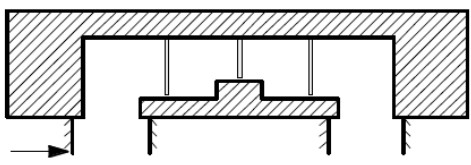

c)

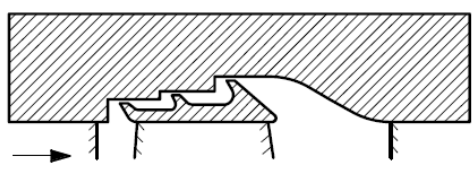

Figure 1: Labyrinth seal geometries - linear seal with more chambers (a), stepped design (b) and seal in application to gas turbines (c), [2].

Various groups of labyrinth seals based on their design and arrangement on the blades tips and on the rotor, are discussed in $[3,4,6]$.

Predicting leakage flow in labyrinth seals dates back to Egli [9], who provided a rational theoretical treatment of the labyrinth problem based on the flow characteristics typical for a sharp edged orifice. In [10] is presented a fluid mechanics approach to the labyrinth seal leakage problem. Many efforts were performed to reduce the leakage mass flow and to improve seals characteristic, [12, 13, 14]. In these works are found and applied for research various empirical discharge coefficients for investigation of different labyrinth seal geometries and applications. Great contribution to the theory of labyrinth seals is provided in [15] and in the review study presented in [16].

In next 3 decades scientists worked to accumulate test data $[9,18,19]$ in order to obtain reliable prediction tools, for flows in seals, based on experimental data [19, 20, 21]. It was proved that analytical models to predict seals performance satisfactory remain difficult to set up. Thus, testing rigs for seal performance is still applied for research purposes, [22].

In last years, together with the development of the CFD techniques, many computational research works were 


\section{International Journal of Science and Research (IJSR) \\ ISSN (Online): 2319-7064 \\ Index Copernicus Value (2013): 6.14 | Impact Factor (2015): 6.391}

fulfilled and models elaborated, targeted to analyze flows inside labyrinth seals [23-28].

In research works discussed in [29, 30, 31] scientists arrived to elaboration of new configurations for the labyrinth seal. Their characteristics were studies [31, 32, 33], and the obtained results show that a good configuration of a seal should be able to provide high rate of kinetic energy dissipation

Based on the literature survey and our experience, it is clear that the effort to enhance the performance of the labyrinth seal would have to be either on developing a new configuration or improving the existing designs.

This research is targeted to design and numerical analysis of a labyrinth seal, which has geometry shown in fig.2. The effort is to attain a seal that has good dynamic sealing properties, higher compliance with the shaft, simple geometry for manufacturing and maintenance, create as high as possible vortex structures and loss of kinetic energy in order to stop the flow of leaks passing through the sealed places of turbine stages. It is known that the shaft of a turbine exhibits modal and stress loads. As a result, there are instances of the impingement of the shaft on the labyrinth seal elements, thus permanently deforming them [3]. That is why seal elements must be designed to resist those loads and operate at maximum efficiency. However, it would be envisaged as future work after a design compatible with above mentioned features, is attained.

\section{Problem set-up}

\subsection{Geometry and numerical set-up}

The purpose of current research is 3D modeling and analysis of labyrinth seal consisted of quadrilateral cavities, fig. 2, which will be implemented to a turbine stage, part of energetic system.

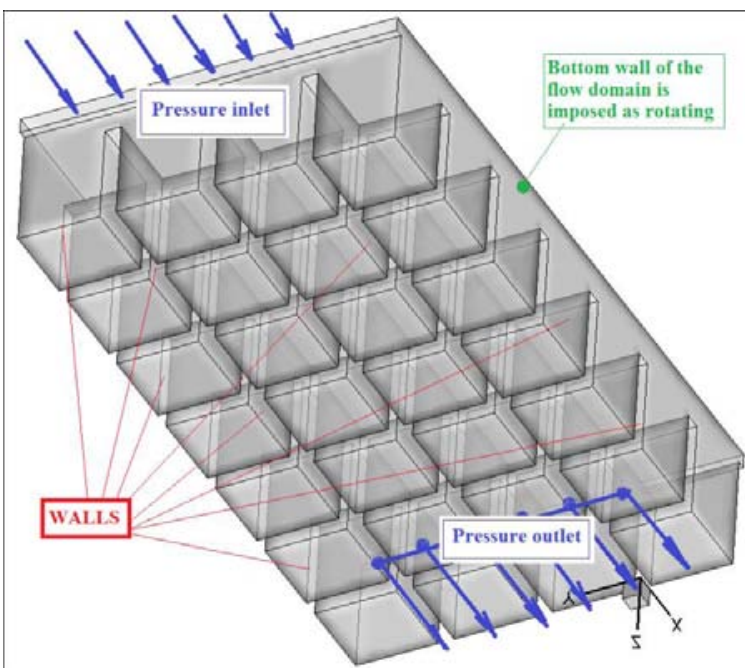

Figure 2: Domain configuration with imposed boundary zones.

The idea of such design is to reduce leakage of fluid by increasing the amount of energy lost through the various mechanisms of energy dissipation in the seal cavities turbulence, circulation, flow-stagnation, etc.

The labyrinth seal geometry is fulfilled in Gambit, with discretization grid, highly refined around streamed walls. The total number of finite volume elements is 135889 .

As work fluid is imposed steady, turbulent and viscous fluid. At the labyrinth seals inlet is imposed boundary zone of type "pressure-inlet", at the outlet - "pressure - outlet". Values of boundary conditions were obtained after a preliminary research of a turbine stage with rotating rotor blade and analysis of results, related to:

- Flow parameters distribution through the stage and especially at the region of the radial gap, fig. 3;

- Secondary flows through the radial gap, fig. 4(a,b).

All walls of the quadrilateral cavities are imposed of boundary type "wall" with no-slip boundary conditions. Bottom wall of the flow domain under consideration is of type "wall" but with defined rotational velocity of $1500 \mathrm{rpm}$, [34].

Constant mass flow rate of leak is imposed in the flow direction. Parameters of leak, flow parameters at inlet and outlet of the labyrinth seal volume are defined after a preliminary analysis of turbine stage, with radial gap, working under definite conditions [34].
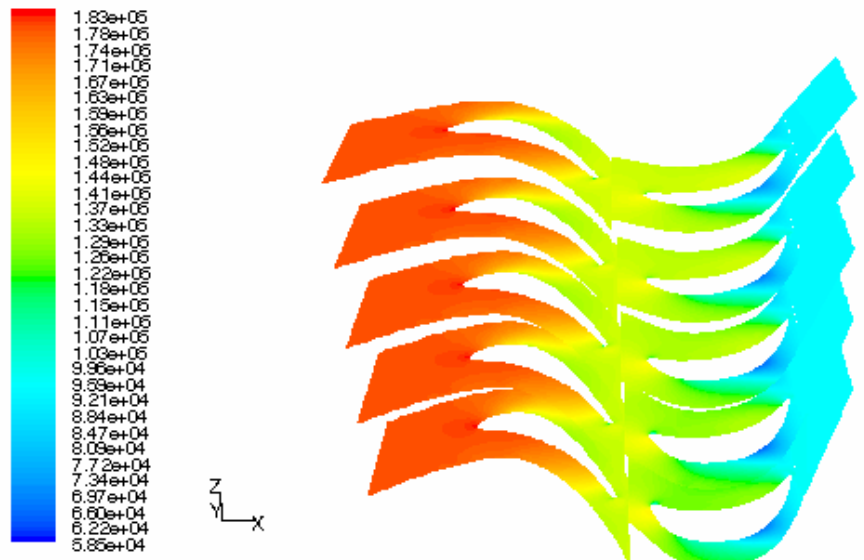

Figure 3: Static pressure distribution in control sections along the blades of turbine stage [34].

As a turbulence closure the Realizable $k-\varepsilon$ model is applied, as proven in [28] to provide reasonable results.

The governing equations are discretized by the Second Order Upwind scheme; exception is the pressure-velocity coupling equation, discretized by SIMPLE scheme. Solutions is obtained with imposed values for all convergence factors equal to $10^{-6}$, exception is the energy equation with factor of convergence $10^{-8}$. 


\section{International Journal of Science and Research (IJSR) \\ ISSN (Online): 2319-7064}

Index Copernicus Value (2013): 6.14 | Impact Factor (2015): 6.391

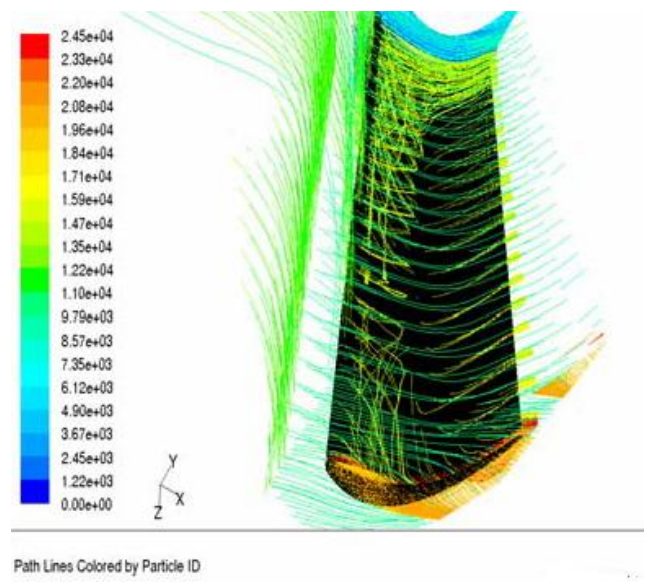

(a)

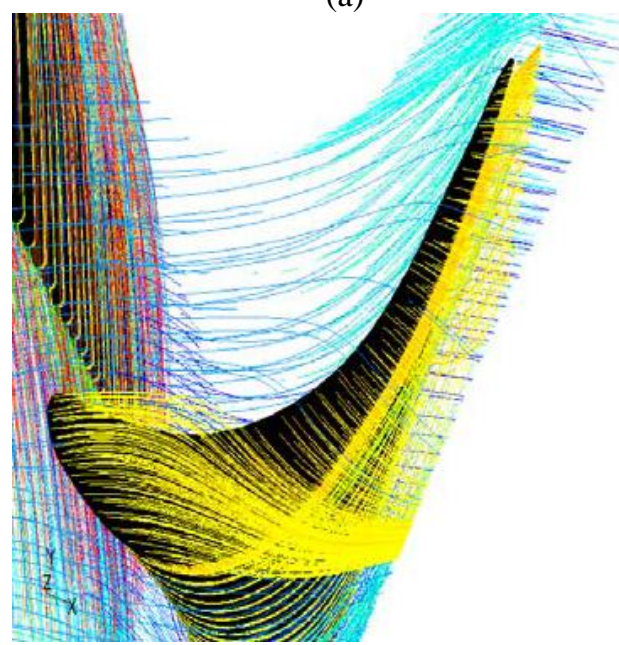

(b)

Figure 4: Secondary flows (a) and fluid through the radial gap (b) in a turbine stage [34].

\subsection{Mathematical Model}

Reynolds averaged Navier-Stokes (RANS) equations are applied to acquire the flow dynamics features of the flow field. RANS equations are as follows:

- continuity equation:

$$
\frac{\partial}{\partial x_{i}}\left(\rho u_{i}\right)=0
$$

-momentum equation:

$$
\frac{\partial}{\partial x_{j}}\left(\rho u_{i} u_{j}\right)=\frac{\partial p}{\partial x_{i}}+\frac{\partial}{\partial x_{j}}\left[\mu\left(\frac{\partial u_{i}}{\partial x_{j}}-\overline{\rho u_{i}^{\prime} u_{j}^{\prime}}\right)\right]
$$

Turbulence model equations are described in [11].

Discharge coefficient describes the real behavior of the seal under consideration and is calculated by eq. (3)

$$
C_{D}=m_{\text {leakage }} / m_{\text {ideal }}
$$

The discharge coefficient depends on the pressure ratio, number of used seals, leakage mass flow rate.

The flow through an ideal labyrinth seal is eq.(4), [17]:

$$
\begin{aligned}
& m_{\text {ideal }}=\left(A \cdot P_{\text {in }}\right) /\left(k \cdot R \cdot T_{\text {in }}\right)^{0.5} \cdot\left\{\left(2 \cdot k^{2} /(k-1) \cdot\left[\left(P_{\text {out }} / P_{\text {in }}\right)^{(2 / k)}-\right.\right.\right. \\
& \left.\left.\left(P_{\text {out }} / P_{\text {in }}\right)^{((k+1) / k))}\right]\right\}
\end{aligned}
$$

where: $A p_{\text {in }}$ - is the gap inlet area; Tin - temperature at inlet; Pout- static pressure at outlet; Pin - static pressure at inlet; $\mathrm{m}_{\text {leakage }}-$ leakage mass flow rate.

Velocity magnitude decreases from inlet to the outlet as the flow passes through the number of seal cavities, fig. 6(a) and fig.5(a). Velocity values at the inlet of the labyrinth seal are $54.8 \mathrm{~m} / \mathrm{s}$ and at the outlet values of magnitude are around $20 \mathrm{~m} / \mathrm{s}$. Realized decrease in kinetic energy of flow is around $60 \%$. In the same time minimum values of turbulent kinetic energy decrease from inlet to outlet, fig. 6(b); the stream lose part of its velocity due to intensive vortex structures and drag effects in cavities of seal chambers, fig. 5(a,b).

Imposed rotational velocity of 1500rpm [34] impacts vortices' distribution in the entire chamber domain, see in fig. 5(a). A significant part of leakage kinetic energy is lost to maintain the vortex structures. At the outlet leakage is characterized with decreased kinetic energy, leading reduction in its flow rate.

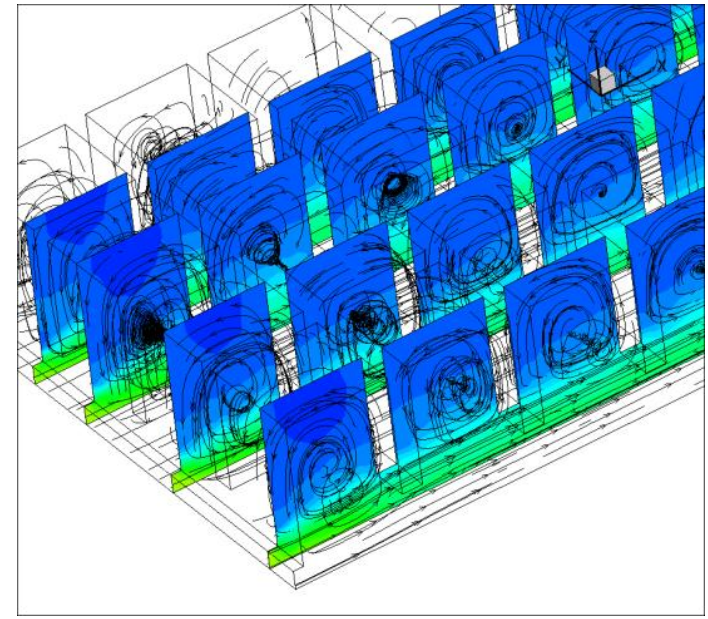

(a)

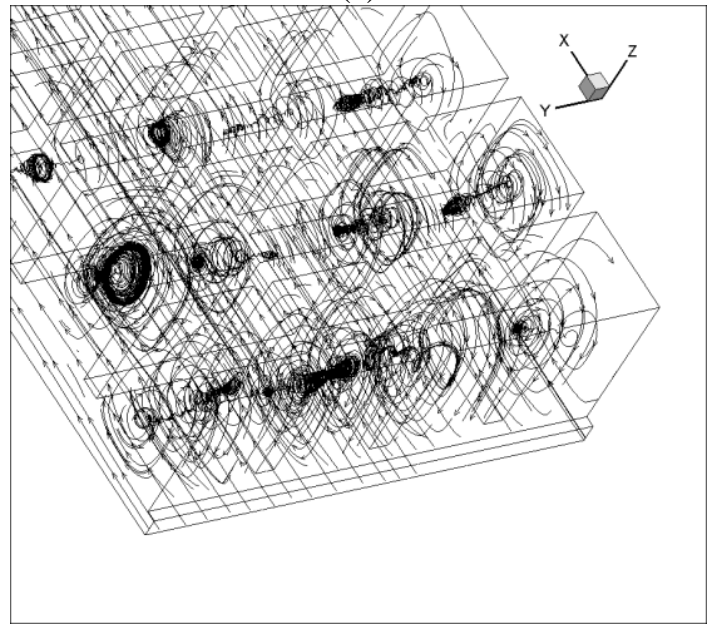

(b)

Figure 5: Velocity vectors and values realized in sections through the seal ( $y=$ const), (a) and visualization of the vortices in seal cavities, (b).

The more chambers the more vorticity structures, thus losses of leakage velocity increase and less discharge coefficient is valid for case under consideration. Throughout this study, the 


\section{International Journal of Science and Research (IJSR) \\ ISSN (Online): 2319-7064}

Index Copernicus Value (2013): 6.14 | Impact Factor (2015): 6.391

discharge coefficient describes the total losses that occur as the fluid flows through the cavities of seal chambers.

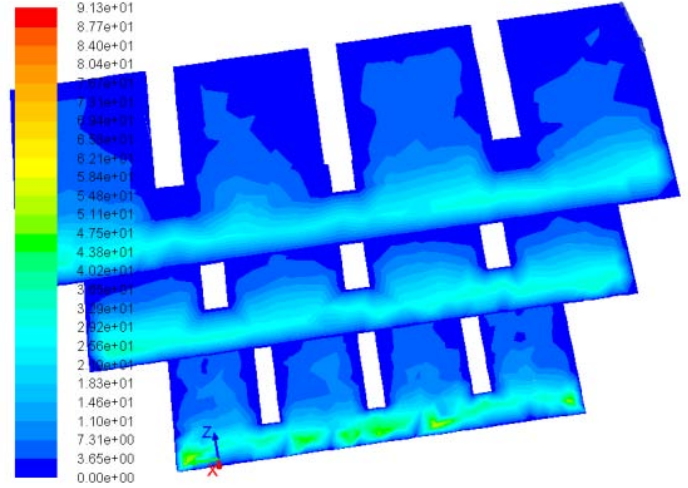

(a)

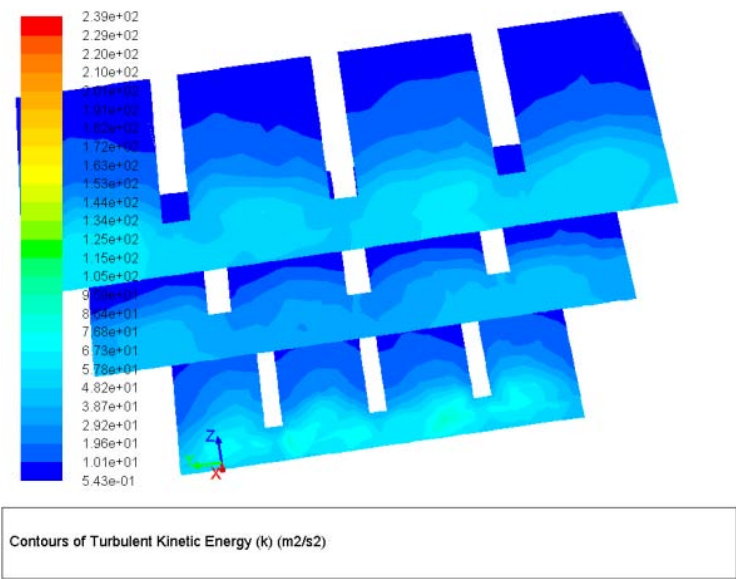

(b)

Figure 6: Velocity field distribution (a) and turbulent kinetic energy (b) in 3 control sections.

In addition, a research on how change in rotational velocity and pressure ratio (pressure at outlet/pressure at inlet) impacts the leakage flow ratio is accomplished. The analysis showed that computed leakage flow rate increases with increasing the pressure ratios calculated for the inlet and outlet and decreases a bit with imposed increase in rotational velocity.

\section{Conclusions}

A three-dimensional RANS solution was accomplished to model and analyze the impact of new labyrinth seal geometry on the possibility to decrease leakage flow rates. The geometry under consideration is simple, easy to manufacture and assemble to the shaft and blade tips.

The proposed design leads to increased vorticity levels in the cavities and decrease of flow rates through the labyrinth seals domain, hence contribute to higher efficiency of turbomachines. Future work is to implement the proposed labyrinth seals into a turbine stage as part of propulsion system and to accomplish a numerical analysis for the entire aerodynamic performance.

\section{References}

[1] Stocker, H.L., "Determining and Improving Labyrinth Seal Performance in Current and Advanced High Performance Gas Turbines," AGARD Conference proceeding no. 237, "Seal Technology in Gas Turbine Engines," April, 1978.

[2] Axel Pfau, Loss Mechanisms in Labyrinth Seals of Shrouded Axial Turbines, Diss. ETH No. 15226 submitted to the ETH - Zürich, 2003.

[3] Sricharan Kishore Ayyalasomayajula, A Numerical Study of Curved Labyrinth Seals for Steam Turbines, University of Tennessee - Knoxville, 12/2005

[4] H. Zimmermann, K. H. Wolff, Air system correlations, Part 1: labyrinth seals, ASME paper 98-GT-206, 1998.

[5] H. L. Stocker, D. M. Cox, G. F. Holle, "Aerodynamic performance of conventional and advanced design labyrinth seals with solid-smooth, abradable, and honeycomb lands", NASA CR-135307, 1977.

[6] R. Paolillo, T. K. Vashist, D. Cloud, F. M. G. Bingen, G. A. Kool, "Rotating seal rig experiments: test results and analysis modeling”, ASME paper GT2006-90957.

[7] S. Wittig, L. Doerr and S. Kim, "Scaling effects on leakage losses in labyrinth seals", Trans. ASME J. Eng. Power, 1983, 105: 305-309.

[8] D. L. Tipton, T. E. Scott and R. E. Vogel, Labyrinth seal analysis - Vol. III : analytical and experimental development of a design model for labyrinth seals, AFWAL-TR-85-2103, 1986.

[9] Egli, A., "The leakage of steam through labyrinth seals", Transactions of the ASME, 1935, 57, pp115-122

[10] G. Vermes, "A fluid mechanics approach to the labyrinth seal leakage problem", Trans. ASME J. Eng. Power, April 1961, 161-169.

[11] www.ansys.com

[12] Wittig, S., Dörr, L., Kim, S., "Scaling effects on leakage losses in labyrinth seals", ASME Journal of Engineering for Power, 1983, 105, pp305-309

[13]Zimmermann, H., Wolff, K. H., "Air system correlations, Part 1: Labyrinth seals", 98-GT-206, ASME Turbo Expo, June 1998, Stockholm, Sweden

[14]Rhode, D. L., Allen, B.F., "Measurement and visualisation of leakage effects of rounded teeth tips and rub-grooves on stepped labyrinths", 99-GT-377, ASME Turbo Expo, June 1999, Indianapolis, Indiana

[15] Trutnovsky, K., Komotori, K., "Berührungsfreie Dichtungen", VDI-Verlag, 1981.

[16] Sneck, H.J. (1974). "Labyrinth seal literature review", Journal of Lubrication Technology-Transactions of the ASME, October 1974, pp579-582.

[17] Saikishan Suryanarayanan, Labyrinth seal leakage equation, MS Thesis, Texas A\&M University , May 2009

[18] Morrison, G.L., and Chi, D., "Incompressible Flow in Stepped Labyrinth Seals," ASME Paper 85-FE-4, Joint ASME/ACSE Applied Mechanics, Bioengineering and Fluids Engineering Conference, Albuquerque, NM, June 24-26, 1985.

[19] Wyler, J.S., "Design and Testing of a New Double Labyrinth Seal," ASME Paper 81-Lub-58, ASME 
Winter Annual Meeting, Washington D.C., Nov. 15-20, 1981.

[20] Stocker, H.L., "Advanced Labyrinth Seal Design Performance for High Pressure Ratio Gas Turbines," ASME Paper 75-WA/GT-22, ASME Winter Annual Meeting, Houston, Texas, Nov. 3 - Dec. 4, 1975.

[21] Wachter, J., Benckert, H., "Flow Induced Spring Coefficients of Labyrinth Seals for Applications in Rotor Dynamics," NASA CP 2133, Proceedings of Workshop on Rotordynamic Instability Problems in High Performance Turbomachinery, May 12-14, 1980.

[22] Hawkins, L., Childs, D., Hale, K., "Experimental Results for Labyrinth Gas Seals With Honeycomb Stators: Comparisons to Smooth-Stator Seals and Theoretical Predictions," Journal of Tribology, vol. 111, Jan., 1989.

[23] S. Wittig, U. Schelling, K. Jacobsen, S. Kim, "Numerical predictions and measurements of discharge coefficients in labyrinth seals", ASME paper 87-GT188, (1987).

[24] V. Schram, K. Willenborg, S. Kim, S. Wittig, "Influence of a Honeycomb Facing on the flow through a stepped labyrinth seal", ASME paper 2000-GT-0291, (2000).

[25] B. I. Soemarwoto, J. C. Kok, K. M. J. de Cock, A. B. Kloosterman, G. A. Kool, "Performance evaluation of gas turbine labyrinth seals using computational fluid dynamics", ASME paper GT2007-27905, (2007).

[26] W. Wang, Y. Liu, P. Jiang, H. Chen, "Numerical analysis of leakage flow through two labyrinth seals", J. of Hydrodynamics, Ser. B, 19 (2007) 107-112.

[27]A. D. Vakili, A. J. Meganathan, M. Michaud and S. Radhakrishnan, S., An experimental and numerical study of labyrinth seal flow, ASME paper GT2005-68224, (2005).

[28] Tong Seop Kim, Kyu Sang Cha, "Comparative analysis of the influence of labyrinth seal configuration on leakage behavior", Journal of Mechanical Science and Technology 23 (2009) 2830 2838

[29] Michaud, M. A., "An Experimental Study of Labyrinth Seal Flow," MS Thesis, University of Tennessee, August, 2002.

[30] Michaud, M., Vakili, A.D., Meganathan, A.J., "An Experimental Study of Labyrinth Seal Flow," Proceedings of IJPGC 2003 International Joint Power Conference, Atlanta, GA, June 16 - 19, 2003.

[31] Vakili, A.D., Meganathan, A.J., Michaud, M.A. Radhakrishnan, S., "An Experimental and Numerical Study of Labyrinth Seal Flow," Proceedings of 70 GT2005: ASME Turbo Expo 2005: Power for Land, Sea and Air, Reno-Tahoe, NV, June 6 - 9, 2005.

[32] "Advanced Steam Labyrinth Seal Design - Phase 1 Initial Concept Evaluation,’EPRI Report 1011932, Final Report, May, 2005.

[33] Vakili, A.D., Meganathan, A.J., Ayyalasomayajula, S., "Advanced Labyrinth Seals for Steam Turbine Generators," Proceedings of GT2006: ASME Turbo Expo 2006: Power for Land, Sea and Air, Barcelona, Spain, May 8 - 11, 2006.

[34] Galina Ilieva, "Numerical modeling and research of a 3D turbine stage", Engineering Applications of Computational Fluid Dynamics, Series: Advanced Structured Materials, Springer, Vol. 44, 2015, pp.103126, DOI: 10.1007/978-3-319-02836-1_8. 